\title{
Reflexivity, relative autonomy and the embedded individual in economics
}

\author{
CHRIS FULLER ${ }^{1}$ \\ Royal Docks Business School, University of East London, UK \\ Email: c.g.fuller@uel.ac.uk
}

\begin{abstract}
This paper is about the mind of the embedded individual in heterodox economics. Beginning from Margaret Archer's analysis of modes of reflexivity and following the respective contributions of Geoff Hodgson and John Davis, the paper seeks to integrate into Archer's approach a place for habitual beliefs and an analysis of the 'relative autonomy' of the embedded individual. Archer's identification of modes of reflexivity is endorsed but her avoidance of any dispositional place for habit in the mind is questioned. It is argued that by excluding habits in this way, Archer, unlike Davis, implausibly assumes most individuals have achieved relative autonomy in their group associations. The essay develops an approach to the mind that articulates underlying relationships between habits and internal conversation, potentially enriching Archer's explanation of modes of reflexivity while locating Davis's notion of relative autonomy within that framework. Specific economic implications are then briefly considered.
\end{abstract}

\section{Introduction}

Heterodox economists and allied social theorists aspire to a conception of the socially embedded self-aware individual to guide public policy oriented to enabling the fullest flourishing of humanity (Davis, 2003). Are habits and a fundamentally interior mental domain where 'internal conversation' occurs an irreducible part of this conception (Fleetwood, 2008)? This paper pursues an affirmative answer to this question building on Margaret Archer's seminal analysis of modes of internal conversation. Major contributions of Geoff Hodgson and John Davis are integrated into Archer's work. Habit is understood to play an important role in explaining modes of internal conversation and can help identify conditions in which the embedded individual achieves 'relative autonomy' from social groups.

This paper is organised as follows. The first section offers two points of departure: a realist ontology and Archer's approach as a platform. The second and third sections offer an interpretation of Archer's 'model' of the embedded individual's mind relative to that proposed by Hodgson. The fourth section explains Archer's identification of modes of internal conversation and questions her systematic avoidance of an habitual disposition in the mind. The fifth section introduces Davis's discussion of collective intentionality and its relevance to individual reflexivity. It is argued that by avoiding a role for habitual beliefs, Archer assumes rather than explains why most people can maintain what Davis calls 'relative autonomy' in their group associations - namely being in control of, rather than controlled by, these associations. Section six then elaborates an approach to the mind that can harness the

\footnotetext{
${ }^{1}$ The author wishes to thank the editor-in-chief and two anonymous referees for their constructive comments and suggestions. The usual disclaimer applies.
} 
serious role for habitual belief generation and usage stressed by Hodgson to enrich Archer's explanation of modes of internal conversation while locating Davis's notion of 'relative autonomy' within Archer's framework. Some specific economic implications are indicated.

\section{Points of departure}

\subsection{Realist social ontology and the embedded individual}

All three social theorists considered in this paper work from a realist ontological position in their portrayal of the 'embedded' individual. Their common ground regarding what it is that constitutes 'reality' is summarised in the following six premises:

Premise 1: There can be no social structure without individuals.

Premise 2: The 'downwards conflation' of social structure to individuals is avoided: that is, social structures are not simply explained by the properties of individuals.

Premise 3: Individuals depend on social structures.

Premise 4: Individuals are not reducible to social structures: that is, the 'upwards conflation' of agents into structure, leading to theoretical analyses of the form 'structures cause structures' with no mediation by an analysis of the actions of and relations between individuals (often referred to as methodological holism and functionalism), is ruled out.

Premise 5: Social structures exist prior to individuals: individuals are 'born into' social structures that temporally pre-date them. This distinguishes the realist position taken here from Anthony Giddens's (1984) 'structuration' theory. This emphasised the 'duality of structure' which 'centrally conflated' agency and structure, compressing them together with unfortunate results for the view of individual action ${ }^{2}$ (Archer, 1995; Mouzelis, 1995).

Premise 6: Social structures have causal powers that (i) are not reducible to individual thoughts or actions and (ii) are only exercised through individual actions. Thus the potential powers of structures are only realised when the exercise of individual causal powers occurs. Beyond these six premises, there are differences over how to characterise 6 (ii).

\subsection{Archer's conception of agency as the starting point}

Although we consider Archer, Hodgson and Davis's approaches to issue 6(ii) above, we shall build on Archer's analysis. To date she provides the most theoretically sustained empirically grounded conception of systematically different types of human mental operation in a realist

\footnotetext{
${ }^{2}$ The individual ends up being seen as 'over-active' with every action transforming structure in some way (Archer, 1995: 117-121); is 'over-social', a social subject with essentially no extra-socially generated private life, especially of the mind (op. cit.: 121-129) and 'under-stratified': structure does not exist as an 'object' towards which the agent can subjectively take a position that can fuel motives for its actions (op. cit.: 129-132).
} 
framework. In the contrast of Hodgson's 'emergentist materialist' approach with Archer's approach of 'causal dualism', no evaluation of the alternative approaches to causality implied by these works is provided. Nor is a synthesis between these approaches to causality advocated. While emphasising an approach consistent with causal dualism, the paper will indicate, where necessary, where those favouring an emergentist materialist approach might pursue a different line of development. No claim is thus made as to the superiority of causal dualism as distinct from emergentist materialism. Instead, this paper concerns itself with the question of how Archer's approach can (and why it should) incorporate Hodgson's and Davis's insights into habits and relative autonomy respectively.

\section{Margaret Archer and the centrality of internal conversation in the conception of action}

Margaret Archer begins from a 'morphogenetic' realist social theory position which holds to 'causal dualism'. Two sets of causal powers are held to exist: those emanating from objective structures, that set up 'situations' in which individuals find themselves and those emanating from the individual's subjectivity as represented by the individual's 'internal conversation' (or 'self talk' or inner deliberation process). Individuals for Archer are simultaneously 'agents', 'actors' and 'persons' (Archer, 1995: 254-7). For her, being human is more than being born a member of a particular collectivity defined by common life chances (being an agent), playing out the scripts of the various positions/situations their life chances 'allow' them access to (being an actor). The human as 'person' also has an inner domain, an 'internal conversation', fundamentally 'interior', uncaused by objective structures and with its own causal powers. Situations cannot cause the individual to do anything without the subjective powers of the individual (the internal conversation) also being involved.

Through the 'internal conversation' a person delineates, deliberates about and dedicates themselves ${ }^{3}$ to what is of most significance to them (their ultimate 'concerns'). Such inner 'work' involves emotional labour. ${ }^{4}$ Individuals form plans of action or 'projects' which they undertake to try to realise these concerns. Archer outlines a 'Three Stage Model' (2007: 17; 2003: 135-148) as follows:

(i) Structural and cultural properties objectively shape the situations that agents confront involuntarily, and inter alia possess generative powers of constraint and enablement in relation to

\footnotetext{
${ }^{3}$ This 'delineation, deliberation and dedication' process is termed the 'DDD scheme'.

${ }^{4}$ The deliberative phase '....[often] entails a visual projection of scenarios seeking to capture, as best the subject is able, the modus vivendi that would be involved, while listening to the emotional commentary that is provoked and evoked when imagining that particular way of life' (Archer, 2007: 20).
} 
(ii) Subjects' own constellations of concerns as subjectively defined in relation to the three orders of natural reality: nature, practice and social.

(iii) Courses of action are produced through the reflexive deliberations of subjects who subjectively determine their practical projects in relation to their objective circumstances.

Thus (i) and (ii) together imply that structured situations (positions and roles) in which individuals are placed involuntarily can affect them emotionally. Archer (2007:19-20) gives examples of how a person can have conscious awareness of the influence of properties of a given situation by its impact on their emotions, without this conscious awareness involving 'full discursive penetration'. For instance, a young academic rapidly appointed to her first editorial board of a journal who finds she is constantly interrupted/ignored/overridden by the (predominantly older, male) academics doesn't need to have fully deliberated on her situation as an instance of female 'tokenism': '...her discomfort is all she needs to know to back out of this potential opening' (Archer, 2007:18). She is nevertheless aware of the feelings produced, and these feelings feed into the internal conversation. The subject also takes into account the emotions that arise from deliberations over their concerns. The internal conversation is thus involved in continually considering these emotional responses, both to its (objective) situation and to its (subjectively defined) concerns. Step (iii) then involves the articulation and rearticulation of concerns through the internal conversation process leading to the formulation of projects, or a set of intentions to act, ultimately causing actions.

\section{Geoff Hodgson and the centrality of habit in the conception of action}

For Geoff Hodgson, the Principle of Evolutionary Explanation 'requires that all assumptions concerning human behaviour should be consistent with our knowledge and understanding of human evolution' (Hodgson, 2003: 171). The Principle '...demands that any behavioural assumption in the social sciences must itself be capable of explanation along (Darwinian) evolutionary lines' (Hodgson, 1998: 188).

Hodgson follows Thorstein Veblen's evolutionary approach in holding that the individual's actions result from instinctive responses and through 'habit'. Habits are dispositions or 'propensities to behave in particular ways in a particular class of situations' and 'are formed through repetition of action or thought'. Habits can remain unused: they are 'submerged repertoires of potential behaviour [and] can be triggered by an appropriate stimulus or context' (Hodgson, 2003: 164). ${ }^{6}$

\footnotetext{
5 'From the pragmatist and institutionalist perspective, habits are foundational to all thought and behaviour. ...all deliberations... themselves rely on habits and rules....In turn....rules have to become ingrained in habits in order to be deployed by agents' (Hodgson, 2003: 166).

${ }^{6}$ Hodgson (2001: 289-90) has stressed the difference between habit as 'behaviour' (i.e. habits as another name for 'repeated actions') and habit as a 'disposition' or 'acquired propensity' in which there is a tendency built into the way the mind works to repeat a given (course of) action when triggered by situations in which that course of action had been pursued in the past.
} 
Central to the situational context facing individuals are 'institutions': namely

...durable systems of established and embedded social rules and conventions that structure social interactions....[Institutions] enable ordered thought, expectation and action, by imposing form and consistency on human activities (op cit).

Institutions create situations that constrain ${ }^{7}$ individual actions. In such situations, individuals are faced with 'rules' ${ }^{8}$, having the general form 'in situation S1 do A1'. If the individual experiences situation S1 again in future, the assumed nature of the mind is such that it is somewhat more likely that the individual will do A1 again. The mind, in other words, has a capacity to generate a predisposition to do A1 again, triggered by situation $\mathrm{S} 1$. This 'predisposition for doing A1' by-passes any conscious deliberation on alternative choices and is what is meant by a 'habit' in the dispositional sense being created.

Hodgson recognises that deliberation, reasoning and calculation occurs, arguing that '...deliberation and reason are deployed to make a choice when habits conflict, or are insufficient to deal with the complex situation' (Hodgson, 2004c: 172).

'Deliberation' is itself habit structured. Hodgson (2003: 170 emphasis added) observes that

...different sets of habits may give rise to competing preferences. A choice is then made, and this choice may itself involve a further cluster of habitual interpretations or predispositions.

So Hodgson treats 'deliberation' on habits as involving a 'higher level' of the mind. At that higher level there may exist 'higher level' habits that structure the way choice happens between habits or can direct the formation of new habits. It is the operation of 'higher level' habit that Hodgson could call 'deliberation'. Moreover, deliberation is guided by 'beliefs' which can themselves become habitual. Beliefs will also structure the deliberation process through influencing expectations and perceptions.

The individual is socially positioned, thereby exposed to various situations. Through the imitation of others in such situations, a person's beliefs are formed and their actions shaped. To the extent that institutional changes and 'cultural selection' can cause changes in the situation and thereby in habits, individuals can be 'reconstituted': they act differently due to changes in habitual actions or due to changes in the habitual way they think or deliberate. This link from institutions to habits is what Hodgson calls 'reconstitutive downwards causation': the reconstitution of individuals via change in their habits.

For Hodgson (2001: 289): 'Emphatically, habit does not mean behaviour. It is not itself a recurrent or repeated act. It is not the same thing as a conditioned response.'

\footnotetext{
${ }^{7}$ This is neither to ignore nor to downplay the enabling role of institutions in guiding actions.

${ }^{8}$ Rules are defined widely to include legislation, regulations, social norms, conventions, expectations and so on.
} 


\section{Building from Archer and Hodgson: The importance of both habit and internal conversation}

Hodgson's Veblenian view of human action draws attention to the mind as layered, each layer operating as an automatic response to external triggers but with links between the layers. The emphasis is on instinct and habit as the unconscious and non-conscious causes of human action. This 'emergentist materialist' view challenges 'causal dualism': rendering potentially unnecessary Archer's concept of the autonomously operating 'internal conversation' process as a separate supplier of causes for human action. I shall uphold Archer's concern to preserve the 'private life of the mind' through causal dualism as her conception of modes of internal conversation provides a rich theoretical canvas on which to analyse different 'types' of structured agency. However, I shall then argue that it is not necessary also for Archer to eliminate a meaningful role for habit to uphold this concern.

\subsection{The concept of modes of internal conversation}

As an 'actor' and 'agent', an individual may be situated in similar contexts, with similar life chances to other individuals in such contexts. However, for Archer that individual is also a 'person' who may have a systematically different mode of internal conversation from (some of) these other persons. Consequently how this individual relates her concerns to her contexts may then systematically differ from (some of) these otherwise similarly situated individuals. ${ }^{9}$ Archer (2003) identified four modes of self talk among her interviewees as part of her research. These modes are not 'personality types' but the brief summary below focuses for clarity on the differences in assumed mode of mental operation across types.

The majority of Archer's interviewees were seen by her to follow three 'modes' or 'types' of self talk, each 'type' taking an 'active' orientation towards their structured situations. Their self talk is described by Archer as 'instrumental', orientated to the formation of 'projects' in the light of situations and concerns.

Firstly, 'communicative reflexives' have past and present lives generally exhibiting a high degree of continuity and repetition or 'contextual continuity' (Archer, 2003: 184-5). They distrust their own internal dialogues and their decisions are the joint result of internal conversation and external conversations with trusted 'similars and familiars', of whom there are usually a relatively large number (Archer, 2003:167-8; 2007: 102). Their ultimate concerns are with specific people and they have relatively little problem 'dovetailing' their concerns (Archer, 2003: 169): their family and friends take priority. Other commitments are

\footnotetext{
${ }^{9}$ An anonymous reviewer noted that Giddens's $(1991,1994)$ consideration of reflexivity covers ground discussed considerably later by Archer. However, as noted in Section 1 (note 2), Archer seeks escape from Giddens's 'over-social' view of the person's mind.
} 
fitted around these. Communicative reflexives thus create and maintain a 'micro-world' around them of 'similars and familiars'. Communicative reflexives are thereby insulated from exposure to objective structural or situational constraints (but also prevented from taking advantage of objective situational opportunities). Their orientation towards the constraints and opportunities offered by objective situations is to 'evade' them, with a consequent tendency to be occupationally and socially immobile.

Secondly, by contrast, 'autonomous reflexives' have a past experience of a contextual discontinuity (Archer, 2003: 212). Left to rely on their own judgement (Archer, 2003: 235), they show decisiveness in decision making (Archer, 2003: 210-211). Their ultimate concerns tend to prioritise work achievements or commitments but they work at maintaining this while seeking fairly to divide their (remaining) time to other people (Archer, 2003: 213). Autonomous reflexives can be very ambitious, can be 'loners' and generally wish to be and see themselves as, self reliant (Archer, 2003: 214). Given these characteristics, autonomous reflexives are well aware of and confident about weighing up opportunities and constraints of objective situations they face. Their orientation towards objective structures is thus 'strategic': they become skilled at knowing and trading off the costs and benefits of the situations they face in order to pursue their work-related concerns and associated projects (Archer, 2003: 253), so tending to be occupationally upwardly mobile.

Thirdly 'meta-reflexives', like autonomous reflexives, also have a past experience of contextual discontinuity (Archer, 2003: 257) and also rely on their own judgement. However, meta-reflexives tend to have a strong ideal view of how they should be, as persons: their ultimate concern is to live in a context in which they can express certain ideals they hold to (Archer, 2003: 258). Often the most self critical of the three modes, their internal conversation is directed at self evaluation and self improvement towards their ideals (Archer, 2003: 255-6). Meta-reflexives have a 'subversive' orientation towards objective structures and situational constraints: they 'absorb' objective costs to uphold their ideals and reject objective benefits inconsistent with their ideals (Archer, 2003: 289, 293). However, metareflexives are equally critical of their situational contexts. Since meta-reflexives often find there is only so much they can do to 'improve' themselves, their awareness of contextual 'incongruity' (for not enabling them to express their ideals whatever they personally do to self improve) grows, leading them to lateral mobility and several career changes to improve their situational context (Archer, 2003: 278). This persistent self and contextual criticism also implies that 'dovetailing' of their concerns is problematic for them.

A minority of interviewees of Archer's 2003 work did not fit the above three categories. Archer calls these 'fractured' reflexives: they engage in self talk and emote about their situations (Archer 2003: 302) but are unable to conduct instrumental internal conversations to form a plan or action or project to deal with them. Archer calls these 'passive' agents, to whom 'things happen' (Archer, 2003: 303-4).

\subsection{The marginalisation of habit}

Archer's rich conceptualisation of four reflexive types nevertheless builds in systematic avoidance of any 'dispositional' interpretation of habit in the mind and second, minimises a place for habit as repeated 'behaviour'. Archer (2007: 29-52, 55-58) carries an extensive 
critical discussion of associated sociological literatures attempting to extend Pierre Bourdieu's 'habitus' concept to encompass reflexivity. Notions of 'flexible' or 'reflexive habitus' (Sweetman 2003: 538) in which conscious reflexive deliberation provoked by continual disruption to established socio-economic patterns itself becomes habitual are for her '...either vacuous or an oxymoron' (Archer, 2007: 55). Archer prefers to exclude a dispositional role for habit. She notes, in her approach, a 'seeming paradox':

It is maintained here that [the unacknowledged conditions of action] have first to be found good by a person before they can influence the projects she entertains. (Archer, 2007: 17 emphasis added).

Archer 'resolves' this 'seeming paradox' by 'being precise about what a subject needs to be aware of in order to be influenced' (2007: 17). Conscious awareness being assumed, the issue becomes of 'what kind' of conscious awareness is needed. Archer notes the young academic who, hailing from Britain, finds participation in international conferences a good experience. She doesn't need to know with 'full discursive penetration' that she is benefitting from Britain's colonial past and its impact on the spread of English language. Instead, 'all she has to recognise consciously and find good is, ...the ease and fluency with which she makes interventions...' at the conferences (2007: 18, emphasis added).

The emphasised phrase is crucial. The young academic may have developed a habit of fluently intervening. Archer assumes she must always be discursively aware of her fluent action. But why disallow the possibility that the young academic may be unaware of her habitual action? Why not allow that she may or may not develop a later awareness of it? Alternatively the young academic may have a belief that it is important to make fluent interventions in international conferences. International conference attendance situations may trigger this belief and she acts on it. Archer's approach implies the academic must be discursively aware that she has this habitual belief. Why not assume awareness of this habitual belief is something the young academic may or may not develop?

Archer holds that the individual knows their own mind 'better than anyone else' (Archer, 2003: 21). Their internal conversation is for her a 'genuinely interior...ontologically subjective and...causally efficacious' (op cit: 2003: 16) domain of interior mental privacy that '...is immune from (i.e. not determined by) exterior causes' (Fleetwood, 2008: 197). To concede that an individual without any discursive awareness frequently performs habitual actions and acts on habitual beliefs makes it possible that third parties can often know more of that individual's own mind than that individual. ${ }^{10}$

Yet Archer accepts that in certain circumstances, third parties can tell us more about ourselves than we know. ${ }^{11}$ Nor does Archer's position require us to assume a priori the absence of habit-as-disposition. It can require us to theorise the process by which individuals

${ }^{10}$ Archer (2003: 20) writes: '...why should it be assumed that...external social influences are immune from internal reflexivity? We have no good reason to do so at all, unless we are committed to a much more dubious proposition, which is that all social influences work behind our backs and therefore cannot be matters for internal deliberation...'

${ }^{11}$ Archer (2003: 38) accepts that '...sometimes another could provide a more accurate diagnosis of one of my attitudes than I did myself (arrogance rather than false humility).' 
could become aware of their habits ${ }^{12}$ thereby preventing themselves being potentially manipulated by third parties (see Section 5 below). Archer's position is thus not necessarily undermined by allowing a dispositional role for habit in the mind.

In the second place, Archer's larger reflections on individual action in a changing world minimise any remaining importance of habit even as repeated behaviour. She argues that

[i]n the third millennium, the fast-changing social world makes it incumbent on everyone to exercise more and more reflexivity in increasingly greater tracts of their lives. (Archer, 2007: $5)$.

Archer further claims that '... 'contextual discontinuity' intensifies throughout modernity, and especially during the transition to nascent globalisation, with the consequence that routine or habitual action becomes decreasingly appropriate for all' (2007: 61).

However, given the increasing pace of life, the world may also be becoming increasingly complex (Hodgson, 1999: 181) placing greater cognitive demands on individuals. If habits can be automatically created and situationally triggered, this can explain how individuals could become 'more reflexive'. Greater individual reflexivity may require the reduction of demands on individual cognitive capacities brought about through the existence of (and further development of) institutional patterns that enable habit formation. Moreover, increasing (Knightian) uncertainty about changing socio-economic reality at times of crisis can increase an individual's 'need' for habit to combat increased anxiety and stress or 'ontological insecurity’ (Lawson 1997: 180; Davis, 2003: 122-3). ${ }^{13}$

\section{Collective intentionality and relatively autonomous individuals}

John Davis maintains that the increasing complexity of the associations contemporary individuals have is likely to make it harder for such embedded individuals to be 'relatively autonomous' (Davis, 2003: 143). Davis understands 'relative autonomy' as a capacity to selfimpose obligations (of participating in any given group) on oneself. I shall argue that Davis's analysis indicates an additional problem with Archer's exclusion of habit-as-disposition in the life of the mind.

\footnotetext{
12 Archer (2003: 20) notes that '[i]t could still remain the case that some social influences are immune from internal deliberations, but the onus would then be on the theorist to delineate these and to justify what accords them this immunity.'

${ }^{13}$ I thank an anonymous reviewer for this point. However, see also Section 6.5 which indicates an inverse link between greater uncertainty and the capacity to act habitually.
} 


\subsection{Davis and the nature of collective intentionality}

Davis considers that the group ${ }^{14}$ is a neglected agent in economics and it is important to '...investigate how individuals' shared intentions facilitate groups acting as agents' (Davis, 2003:133). Although only individuals form intentions (and therefore, to avoid Methodological Holism it cannot be held that 'The group itself believes and intends to do X'), individuals can have intentions about groups. To have a collective intention is not simply another way of describing some kind of societal constraint (2003: 139). A collective intention is voluntarily held, but involves the individual binding themselves to it as a result of the group participation that is involved: '...expressing a shared intention commits an individual to an intention held by others...The individual is bound...but voluntarily so' (2003: 131).

Davis makes the case for collective intentions being neither reducible to another form of instrumental rationality ('I adopt [the beliefs of members of that group] because it is in my interest to do so') nor to a form of 'we-preference' ('I prefer to adopt the beliefs of members of that group') (2003: 139-42).

A collective or 'we-intention' can be said to satisfy two conditions: first, 'an individual expressing a we-intention believes this intention is held by other group members' (Davis, 2003: 134) and second, '...an individual expressing this we-intention believes it is mutually held by members of the group' (in other words, person ' $h$ ' believes that others in group $G$ believe ' $h$ ' to believe what they themselves believe) (2003: 134).

\subsection{Collective intentionality, reflexivity and the 'relative autonomy' of individuals}

Davis's approach to reflexivity is to draw attention to what is involved with group participation. Davis links collective intentionality to individual reflexivity by assuming that

...all group members are more or less continually engaged in evaluating and re-evaluating whether they are correctly expressing group intentions on how the group is organised and how tasks and rights are allocated in it (Davis, 2003: 138).

Thus if individual ' $h$ ' has an incorrect understanding of what other group members believe or if ' $h$ ' erroneously thinks that others in that relevant group believe ' $h$ ' has the same views as they do, then the other members of the group could say to ' $h$ ': 'you say we will do this but we have no intention to do it'. This 'feedback' then '...compels individuals in error to re-evaluate what they say and believe' (2003: 138). To the extent that this 're-evaluation' 'takes the form of their asking themselves why their own views are at odds with those of others' (2003: 138) then reflexive behaviour is entailed here.

\footnotetext{
${ }^{14}$ Davis defines a social group as '...(a) a plurality of individuals tied to one another by (b) some principle of membership that implies (c) a system of rights and obligations' (2003: 133).
} 
Davis notes that with continual changes in group association in complex societies, individuals can tend to lose (what he terms) their 'relative autonomy': '...they cease to function as independent distinguishable individuals and instead become enmeshed in ever changing social relationships' (Davis, 2003: 156). Individuals, Davis suggests, often are 'oversocialised' (Granovetter, 1985):

...rather than be able to exercise a reflexive capacity to self impose social group requirements upon themselves, others impose social requirements upon individuals (Davis, 2003: 156-7).

With an ever-more complex social world, 'oversocialisation' becomes more likely. Davis does not, however, think that this argument writes the individual out of socio-economic analysis. He distinguishes between 'capacities' and 'capabilities'. A 'capacity' is 'a power that may or may not be exercised' (2003: 158). A 'capability' 15 is 'a power that has been developed and cultivated so as to be susceptible to regular exercise' (2003: 158). Capacities and capabilities are related. 'One...develops certain capabilities when one has the capacities for doing so' (2003: 158). Davis argues that the potential relative autonomy of the embedded individual depends on the individual having the capability to freely participate in and move across group affiliations, which in turn depends on developing a capacity to self-impose group requirements on themselves. Davis then notes that if embedded reflexive individuals are oversocialised, then they 'are unable to regularly exercise this capacity [to self-impose group requirements on themselves]' and so 'accordingly do not develop the capability for [freely exploring the various opportunities for participating in and moving across various social group affiliations]'(2003: 158). This 'individuating capacity' is 'inherently possess[ed]' by people (2003: 158), argues Davis, yet he considers that 'many, perhaps most' (2003: 159) individuals fail to develop this capacity. Nevertheless, Davis (2003: 160-3) argues that the socially embedded reflexive individual he portrays is not simply meant to describe reality but also to serve as a policy ideal: 'Reasoning dynamically, heterodox thinking judges that, if most individuals are not self-determining, that some are creates an agenda for replacing a pure ideal with one that can be made real' (2003: 163).

\subsection{The achievement of relative autonomy: habits and 'inner conflation'}

Archer assumes most individuals, through instrumental internal conversation, consciously choose projects on the basis of their 'concerns'. Given Davis's argument above, such instrumental self talk and project choice must also include the individual's choice of groups to belong to and choice of the group obligations to bind themselves to. In this light, Archer's approach amounts to the assumption that 'relative autonomy' from groups follows from being able to conduct an instrumental internal conversation. Thus communicative, autonomous and meta-reflexives are automatically relatively autonomous. Davis by contrast assumes many, perhaps most, individuals lack relative autonomy and are 'oversocialised', so directing

\footnotetext{
${ }^{15}$ Davis (2003, especially chapter 8) draws on Amartya Sen's work (for instance Sen, 1985).
} 
attention to how it is individuals can move from being oversocialised to being 'nonoversocialised'.

I now pursue this difference between Davis and Archer further. Suppose, following Hodgson, that in Archer's approach the mind now has a disposition to generate habitual beliefs. I suppose that (at least some) habitual beliefs are automatically acquired by individuals through group participation. ${ }^{16}$ I suggest that the movement away from oversocialisation involves individuals becoming aware of influences upon them from their social group participations and obligations that they were (previously) not discursively aware of. We can then infer that individuals are non-oversocialised when they are able to notice and inquire into their own automatic thought patterns (i.e. habitual beliefs) and can 'integrate' them into concerns. 'Integration' involves two stages. First, a discursive awareness of habitual beliefs arises: they become recognised, by the individual, as 'concerns'. Second, these new concerns are then (i) added to existing concerns or (ii) used to replace some existing concerns or (iii) are discarded as inconsistent with existing concerns. ${ }^{17}$ In short, I suggest, persistent vigilance about inquiring into one's habitual beliefs (sustained integration over time) can generate relative autonomy from group influence, thereby achieving non-oversocialisation.

Now Davis sees the development of this capacity for relative autonomy as an issue for all individuals: so whether and how individuals can achieve the above 'integration' of habitual beliefs into conscious concerns matters for theory and policy. By contrast, Archer's 'active agents' already have relative autonomy, so the issue of 'integration' does not arise for them. Archer theorises as if all habitual beliefs are always, instantly and unproblematically integrated into conscious concerns by active agents. The possible reality of habitual belief formation for most people (i.e. 'active' agents) is ignored. There is an 'inner conflation' of habitual beliefs with conscious concerns in Archer's approach to active agents.

What inner conflation loses for Archer is the more plausible possibility that while most individuals may (as she holds) be 'active' agents (they undertake instrumental internal conversations), many, perhaps most of these individuals could (as Davis implies) also fail to experience relative autonomy. Their actions are partly driven by habitual beliefs internalised from their group participations that operate within their instrumental internal conversations, with such beliefs simultaneously unintegrated into their conscious concerns.

\footnotetext{
${ }^{16}$ In the same way that a person who has lived a life in London and then spends three years in New York will nonconsciously adopt speech and thought patterns associated with groups of New Yorkers, and may only become aware of doing so when their new 'mid Atlantic' accent or subtly changed views are pointed out to them by their former acquaintances once back in London.

${ }^{17}$ Suppose a self-consciously liberal-minded academic is concerned to treat all students from whatever background without prejudice. Then they internally discover that they have repeatedly acted in the past on a previously unacknowledged habitual prejudice against a particular grouping of students. Once 'uncovered' and transformed into a conscious concern, they discard it as inconsistent with their other concerns.
} 


\section{On the capabilities of the embodied mind}

I follow Davis in holding relative autonomy to be an ideal rather than an existing state of affairs and seek to drop inner conflation. However, can the essential autonomy of the internal conversation be retained after dropping inner conflation? Does abandoning inner conflation require abandoning causal dualism and embracing emergentist materialism? I address this issue first.

\subsection{Habit as cause of the internal conversation process}

Suppose the mind was assumed to have a propensity to form habits automatically given its situations, and that habits determine the operation of any given mode of internal conversation. How might this be understood? In Archer's model of the process of the internal conversation itself, ${ }^{18}$ the individual engages in a dialogue between their 'subject-self' which makes utterances (judgements, statements etc) and their 'object-self' which 'listens' and 'records' what was uttered ${ }^{19}$, presenting it back to the subject-self for further reflection: 'Confronted by 'listening' to the articulated thought, the subject confronts her object'(Archer, 2003: 98). ${ }^{20}$ There is subsequent further recording of the subject-self's further utterances and so on.

Archer assumes that the subject-self, the object-self and the process of the subject-self/objectself interaction are immune from causation by external structure. Emergentist materialists however, could assume that the object self/subject self interaction is fully characterised as an instinct-habit process. Deliberation ('internal conversation') would be the emergence and operation of 'higher level' habits in a layered conception of mind, with mind in principle fully understood as a set of material causes structured by habit and instinct.

Archer is committed to causal dualism, the view that the causal powers of persons are different from those of structures. A causal dualist position must identify a part of the internal conversation process that is immune from causation by material or objective structure.

\footnotetext{
${ }^{18}$ Archer (2003: chapter 2) traces the way pragmatist philosophers William James and C.S. Peirce worked on the notion of 'reflection', with James shifting it from inner 'observation' and mere 'memory' recovery to a process of listening to oneself essentially as monologue (this was where James's enquiry ended). Peirce then pushed the concept of the inner conversation to a point that Archer claims satisfies the three requirements of interiority, subjectivity and causal efficacy. She considers the later, better known work of G.H. Mead on the inner dialogue as a wrong turning and wishes to build on James and Peirce.

${ }^{19}$ The object-self is 'presented as recording the gist of the subject-self's utterance, upon which the latter reflects and then responds as subject to object' (Archer, 2003: 101).

${ }^{20}$ Archer sees this process of dialogue between 'subject-self' and 'object-self' as a development of William James's notion of a two step process in thought. The first step involves 'dimly conceiving a notion', an 'uncrystallised notion': the subject has a 'premonitionary perspective on what she is about to think' (Archer, 2003: 98). This Archer treats as the utterances of the subject-self. The second step for James was the articulated thought: 'selecting the words to express it' (op cit: 98). This is the verbal formulation provided by the object-self.
} 


\subsection{Habit and an autonomous internal conversation process: a dual concept of mind}

Archer depicts the process of the internal conversation as a turn-taking interaction between the object self and subject self. To maintain causal dualism therefore we assume the subject self is fully autonomous from material causes (i.e. instincts and habits), while accepting the object self could be habit structured. The ultimate interiority, subjectivity and causal efficacy of the internal conversation is preserved: the object-self/subject-self turn taking process is not fully characterised as an instinct-habit structure. Instead, we ask: how might habit affect the mode, rather than the process, of internal conversation?

In order to address this question, we give more structure to the concept of mind. Dropping inner conflation, we explicitly distinguish habitual beliefs beyond immediate discursive awareness from 'concerns' available to discursive awareness. We assume the fully developed mind is a dual structure, with habitual action and habitual beliefs generated in a manner outlined by Hodgson, but with a simultaneously operating internal conversation process operating in a manner outlined by Archer. We assume therefore that individuals continually generate a residue of objective structure ('internal structure') within their mind in the form of automatically created habitual beliefs beyond immediate discursive awareness. We assume these habitual beliefs are created simultaneously with, and on a different level of the mind to, the operation of the internal conversation. We assume there are relationships between these levels of the mind. Human agency therefore involves not only an interaction between the embodied person and 'external' structure but also interactions between 'internal' structure (acquired habitual beliefs) and the subjective part of the person's embodied mind (internal conversation).

\subsection{A hierarchy of capabilities of the mind}

To develop the above dual structure conception of the mind, we adopt Davis's 'capabilities'/'capacities' distinction and assume that the mind has four 'capabilities' C1-C4:

(C1) The capability to generate actions automatically, triggered by particular situational contexts (the mind's ability to produce habitual actions); (C2) The capability to generate beliefs automatically that can be subsequently triggered by particular situational contexts (the mind's ability to produce automatic judgements as 'habitual beliefs'); (C3) The capability to engage in 'instrumental' self talk (the mind's ability to form projects or plans of action in the external environment to attempt to realise the individual's principal concerns); (C4) The capability to engage in 'inner-directed' self talk (the mind's ability to treat aspects of the individual's own mental functioning as an object for further inquiry).

Secondly, we can assume that each 'capability' is enabled by a corresponding 'capacity' (E) of the mind. So there are four capacities E1- E4 corresponding to capabilities C1-C4.

Third, we assume, following Hodgson, that C1 - C4 are a hierarchy of 'levels' of mind. C1 and $\mathrm{C} 2$ are the two 'lower' levels at which the mind works 'automatically' in the Hodgsonian 
sense. These two lower levels of the mind can be understood as parts of 'objective external structure' that have become 'objective internal structure' within the embodied mind-brain.

C3 and C4 are the two 'upper' levels at which the mind works reflexively as a subjective process of internal conversation, separate from objective structure (both internal and external) in the Archerian sense. The operation of mind at capability levels (C3, C4) neither causes nor is wholly caused by the operation of mind at capability levels $(\mathrm{C} 1, \mathrm{C} 2)$. However, there are relationships between the 'lower' and 'upper' parts of the mind.

Fourth, we make assumptions about the possible nature of these relationships. We first assume a particular relationship between $\mathrm{C} 2$ and $\mathrm{C} 3$ : the self talk turn-taking process can employ habitual beliefs as 'gut feelings' to terminate particular instrumental internal conversations by justifying particular judgements. Whether and the extent to which habitual beliefs are invoked within internal conversation depends on the mind's relative capacity for instrumental internal conversation, denoted E3. Given E3, the greater the number of habitual beliefs an individual has and the wider the range of situations in which these may be triggered, the greater the individual's automatic employment of habitual beliefs in instrumental internal conversation.

We second assume a relationship between $\mathrm{C} 2$ and $\mathrm{C} 4$ : the self-talk turn-taking process can be directed at making more explicit certain patterns - the habitual beliefs - of the individual's mind. ${ }^{21}$ Which habitual beliefs are scrutinised and how they are scrutinised depends on the internal conversation process $\mathrm{C} 4$ itself. However, whetherlthe extent to which they are scrutinised depends on the capacity E4 of the individual's mind for 'inner directed' internal conversation.

\subsection{Habits, modes of reflexivity and relative autonomy: six hypotheses}

These assumptions about the relationship between habitual beliefs and internal conversation offer directions for future research that Archer's avoidance of a dispositional role for habit in the mind (and consequent inner conflation) misses.

First, Archer suggests communicative reflexives, unlike autonomous and meta-reflexives, have much less faith in their ability to reach decisions by their own self talk alone. The concept of 'breadth' of habitual beliefs may deepen Archer's explanation here. ${ }^{22}$ I suggest

\footnotetext{
${ }^{21}$ Archer's 'discernment, deliberation, dedication' (DDD) sequence tends to assume concerns are 'there' in explicit form at the 'beginning' of the DDD process. Instead we suggest that at least some concerns arise from each individual's capacity E4 to direct internal self talk to scrutiny of habitual beliefs.

${ }^{22}$ It is not necessary to the argument here to invoke specific kinds of habitual beliefs when invoking the 'breadth' concept. Further, although habitual beliefs are by definition beyond discursive awareness (making empirical observation difficult), critical realism/realist social theory posits the reality of 'deep' mechanisms beyond direct empirical observation and sees it as legitimate to invoke them for explanatory purposes.
} 
Hypothesis 1: Autonomous reflexives have a 'breadth' in their habitual beliefs that communicative reflexives do not have. Autonomous reflexives have access to a range of automatic judgements that they can make about various situations because their habitual beliefs are numerous and wide in scope. Communicative reflexives have not produced for themselves a numerous and wide array of habitual beliefs as 'gut feelings' to be used for making judgements within their own self-talk, so they are observed by Archer to rely more on the judgements of others.

I suggest also Hypothesis 2: that this difference of 'breadth' could be caused by the greater 'contextual discontinuity' Archer claims the autonomous reflexives have experienced, relative to the communicative reflexives. Exposure to a greater variety in objective contexts (an implication of 'contextual discontinuity') is likely to produce more situations in which the repertoire of habitual actions at mind level $\mathrm{C} 1$ is either inadequate or clashes occur. At level $\mathrm{C} 2$, the mind may respond to such situations by automatically predisposing the individual to 'look outward' for external guidance as to what to do. Features of the objective situation ('rules') can then become internalised as 'beliefs'. To the extent that such situations are repeated, then such beliefs are automatically invoked: they become habitual beliefs. The mind then has an array of dispositions to judge particular situations in particular ways. I am then suggesting that the instrumentally oriented internal conversation - at level C3 - is able to make use of these automatic dispositions to judge certain situations as an instrument to (potentially more rapid) decision making. The greater availability of such automatic judgements to those individuals subject to more past variety in situational exposure (greater 'contextual discontinuity') may serve to foreshorten their internal conversations so helping to explain why decision making by such 'autonomous reflexives' is more rapid.

Second, what is it that causes individuals who are self-reliant in their decision making to be meta-reflexives rather than autonomous reflexives? Archer sees meta-reflexives as influenced by contextual incongruity (rather than the autonomous reflexives' contextual discontinuity) '...in relation to their dreams' (Archer, 2007: 155). 'At some point', Archer argues, metareflexives '...encountered an incongruity between what they would become - their aspirant vocation or the preconditions for it - and their social context, which impeded its realisation' (2007: 155). However, Archer is less clear on the process within the internal conversation that produces this 'point' in meta-reflexives' lives. I suggest that the way habitual beliefs and the internal conversation interact may be different between persons with one of these two dominant modes.

Consider then Hypothesis 3: the internal conversation of the meta-reflexive is relatively more oriented to treating its habitual beliefs as objects to be transformed into explicit 'concerns' in a process of self-examination, and less oriented to using habitual beliefs as automatic judgements. ${ }^{23}$ Thus it may at least partly be because meta-reflexives actively engage in the 'integration' of acquired habitual beliefs into concerns (unlike autonomous and communicative reflexives), that meta-reflexives are relatively more likely to notice such 'incongruous' moments in their lives, prompting their characteristic lateral mobility. I also

\footnotetext{
${ }^{23}$ The meta-reflexive has some development at all four capability levels $\mathrm{C} 1-\mathrm{C} 4$, while the autonomous reflexive has relatively greater $\mathrm{C} 3$ development, in place of $\mathrm{C} 4$ development.
} 
suggest the related Hypothesis 4: the 'strategic' orientation to external structures demonstrated by autonomous reflexives is at least in part due to their lack of inquiry into their gut feelings. $^{24}$ I further suggest Hypothesis 5: Davis's desired state of individual 'relative autonomy' or non-oversocialisation may rest on more individuals having a developed capability level C4 (as is characteristic of meta-reflexives). Those with developed C4 are then most likely to become aware of habitual beliefs they have non-consciously acquired though their group participations.

Finally, why are Archer's fractured reflexives 'passive' agents? ${ }^{25}$ I offer Hypothesis 6: relative to 'active' agents, 'passive' agents may be more dependent on habitual beliefs and actions (they have access to capacities E1 and E2 and so may have highly developed capabilities $\mathrm{C} 1$ and $\mathrm{C} 2$ ) but lack capacity (E3) for instrumental internal conversation. Inquiry into the basis of these capacities is therefore indicated. Social structures and institutions are likely to play a role in enabling or disabling these capacities. ${ }^{26}$

To maintain inner conflation prevents pursuance of these hypotheses. The 'breadth' of a person's habitual beliefs, the relationships between their habitual beliefs and their internal conversation and the relative capacities behind these habit capabilities and internal conversation capabilities are disregarded under inner conflation. Yet, we have suggested, to include habit in this way does not have to undermine the ultimate interiority, subjectivity and causal efficacy of the internal conversation, if, as a causal dualist this is what one wishes to maintain.

\subsection{Some implications for heterodox economics}

Can the somewhat abstract arguments above offer more direct guidance to research into heterodox economic analysis of individual behaviour? We very briefly consider three directions.

First, (Post Keynesian) heterodox economists could enrich their analysis of individual resource usage and acquisition by exploring the links between dominant modes of reflexivity and empirically recognisable socio-economic groupings. Is there a greater prevalence of addictive consumption among groupings containing (the more habitual) fractured reflexives? Are there systematic differences in the use of informal relative to formal information

\footnotetext{
${ }^{24}$ Consider the entrepreneur and the dynamic corporate CEO as autonomous reflexives. These are what they are at least in part because they are driven by self-unexamined aspects of their mental functioning (unexamined habitual beliefs), their internal conversations harnessing these for (in Archer's phrase) 'performative achievement'.

${ }^{25}$ Archer assumes fractured reflexives are 'damaged' by a serious lack of 'contextual continuity' in their past. However, Archer also invokes a lack of contextual continuity to distinguish between communicative and autonomous reflexives. The concept of contextual continuity/discontinuity seems to do a lot of different causal work for Archer. Progress in dimensionalising the 'contextual continuity' concept could be helped by adding structure to the concept of mind as argued for here.

${ }^{26}$ To the extent that such capacities can be shaped by institutions, another channel of 'reconstitutive downward causation' may operate, besides that Hodgson identified from institutions to habits.
} 
channels between groupings respectively intensive in communicative and autonomous reflexives? Is there a clear tendency to spend to both create and to maintain 'micro-worlds' by groupings rich in communicative reflexives and what kinds of expenditures are entailed? Might one observe more aspirational and more 'self-help' oriented spending but also relatively high savings ratios from groupings strongly featuring autonomous reflexives? Could groupings intensive in meta-reflexives exhibit a relatively stronger resistance to advertising influence and emulative pressures and show a more 'principled' ethical sensitivity (maintaining this stance during recessions more than other groupings)?

Second, at the macro level, one might deepen the heterodox behavioural linkage from uncertainty to Keynes's (once more extremely pertinent) concept of liquidity preference. Consider the following hypothesis: Increased uncertainty (as in the current financial crisis) undermines the basic trust of all reflexive types in the ongoing stability of structures, which reduces the confidence of individuals in their own habitual action repertoires (the mind's level one capacity El for habitual action is weakened). ${ }^{27}$ As a result, the mind's level one capability to perform habitual actions (C1) is inhibited under increased uncertainty. So inhibited, individuals (and their associated organisations) find it more important to be able to delay actions. The preference to hold/hoard cash - as a means by which (spending-related) actions can be delayed in a contract-using monetary production based capitalist economy correspondingly strengthens. Greater uncertainty may therefore result in structurally induced inhibitions on habitual action performance with the observable systemic counterpart being increased liquidity preference.

Finally, Len Doyal and Ian Gough's (1991) pioneering welfare analysis identified individual needs for (physical) 'health' and 'critical autonomy' (broadly the ability to engage critically with socio-economic structures/institutions). The role they identify of various 'societal preconditions' for need satisfaction may be clarified by a more explicit view of mind. Human need satisfaction may also require a balanced development across all four mind capabilities. No reflexive 'type' is necessarily both 'healthy' and 'critically autonomous' as all types can be unbalanced in their mind capabilities. Further, it may be that some or all existing capitalist socio-economic structures may promote (and even require) unbalanced capability development across individuals (perhaps relative overdevelopment of capability C3?). Investigation into the nature of the four 'capacities' that enable mind capabilities to develop is urgent. Such capacities may be, as with E1 above (confidence), and as implied by Doyal and Gough (1991), culturally/institutionally formed and developed. Heterodox economists might then identify those structures and institutions supporting such capacities since this may enhance need satisfaction.

\footnotetext{
${ }^{27}$ It was earlier noted that greater uncertainty (about a changing reality) increases the need for habits. However, this argument presupposes that the capacity to perform 'needed' habitual actions is not also affected by uncertainty. Our hypothesis challenges that presupposition.
} 


\section{Conclusion}

This paper has brought three sets of relevant insights on human agency together, choosing to start with Margaret Archer's insightful identification of different modes of internal conversation. However, Archer avoids a dispositional place for habit, a particular strength of Geoff Hodgson's work. By doing so, it was held that Archer inwardly conflates 'concerns' with habitual beliefs, closing off both a way of deepening understanding of 'modes of reflexivity' and a possible synthesis between internal conversation analysis and John Davis's approach to collective intentionality. The view proposed here sought to protect the ultimate autonomy (interiority, subjectivity and causal efficacy) of the internal conversation, but avoid inner conflation. A dual idea of mind was proposed, understood as a layered hierarchy operating at different 'capabilities', the latter dependent on enabling 'capacities'. In this proposed view, relative autonomy from groups is not the already-achieved 'state of being' of 'active' agents as Archer appears to hold. Following Davis's lead, relative autonomy is seen as an ideal: the 'individuation' from objective structure that a minority (most probably but not exclusively meta-reflexives) achieve by sustaining integration of habitual beliefs into concerns. The majority of individuals lack relative autonomy: unintegrated habitual beliefs may drive their thoughts and actions both instead of instrumental internal conversation (as with fractured reflexives) and through their instrumental internal conversation (as with communicative and autonomous reflexives). Six specific theoretical hypotheses were advanced and some economic implications for spending patterns, macroeconomic functioning and human welfare were briefly indicated.

\section{References}

Archer, M. S. (1995), Realist Social Theory: A Morphogenetic Approach, London: Routledge.

Archer, M. S. (2003), Structure, Agency and the Internal Conversation, Cambridge: Cambridge University Press.

Archer, M. S. (2007), Making Our Way Through the World, Cambridge: Cambridge University Press.

Davis, J. (2003), The Theory of the Individual in Economics, London: Routledge.

Doyal, L. and I. Gough, (1991), A Theory of Human Need, London: Macmillan.

Fleetwood, S. (2008), 'Structure, institution, agency, habit and reflexive deliberation', Journal of Institutional Economics, 4 (2): 183-203.

Giddens, A. (1984), The Constitution of Society, Cambridge: Cambridge University Press.

Giddens, A. (1991), Modernity and Self Identity, Oxford: Polity Press.

Giddens, A. (1994) 'Living in a post-traditional society', in U. Beck, A. Giddens and S.Lash, Reflexive Modernization, Cambridge: Polity Press. Granovetter, M. (1985), 'Economic action and social structure: The problem of embeddedness,' American Journal of Sociology, 91, 481-510.

Hodgson, G. M. (1993), Economics and Evolution, Cambridge: Polity.

Hodgson, G.M. (1998), 'The approach of institutional economics', Journal of Economic Literature, 36: March, 166-192. 
Hodgson, G.M. (1999), Economics and Utopia: Why the Learning Economy is not the End of History, London: Routledge.

Hodgson, G.M. (2001), How Economics Forgot History: The Problem of Historical Specificity in Social Science, London: Routledge.

Hodgson, G.M. (2002), 'Reconstitutive downward causation: social structure and the development of individual agency', in Edward Fullbrook (ed.) Intersubjectivity in Economics: Agents and Structures, London and New York: Routledge.

Hodgson, G.M. (2003), 'The hidden persuaders: institutions and individuals in economic theory', Cambridge Journal of Economics, 27, 159-175.

Hodgson, G.M. (2004a), 'Reclaiming habit for institutional economics', Journal of Economic Psychology, 25, 651-660.

Hodgson, G.M. (2004b), 'Darwinism, causality and the social sciences', Journal of Economic Methodology, 11(2) June, 175-194.

Hodgson, G.M. (2004c), The Evolution of Institutional Economics: Agency, Structure and Darwinism in American Institutionalism, London: Routledge.

Hodgson, G.M. (2009), 'Choice, habit and evolution', Journal of Evolutionary Economics (mimeo).

Lawson, T. (1997), Economics and Reality, London: Routledge.

Mouzelis, N. (1995), Sociological Theory: What Went Wrong?, London and New York: Routledge.

Sen, A. (1985), Commodities and Capabilities, Oxford: Oxford University Press.

Sweetman, P. (2003), 'Twenty-first century dis-ease? Habitual reflexivity or the reflexive habitus', Sociological Review, 51(4), 528-49. 